\title{
SERRATUS ANTERIOR PLANE BLOCK FOR RIB FRACTURES IN THORACIC TRAUMA PATIENTS - CASE SERIES
}

\author{
Nataša Ilić1, Vladimir Vrsajkov', Arsen Uvelin'1, Radomir Ilić2 \\ ${ }^{1}$ Clinical center of Vojvodina, Emergency center, Department of anesthesiology and intensive care, \\ Novi Sad, Serbia, ${ }^{2}$ Clinical center of Vojvodina, Emergency center, Department of emergency \\ surgery, Novi Sad, Serbia
}

\section{Background and aims}

Pain management for patients with chest
trauma rib fractures can be challenging.
Recently, ultrasound guided serratus anterior
muscle plane block has emerged as alternative
analgesic technique to traditional intravenous
opioid analgesia, epidural and paravertebral
blocks, with minimal side effects.
The aim of this case series was to show that
the serratus anterior plane block could provide
effective analgesia for patients with multiple
rib fractures.

\section{Methodology}

- 12 patients with multiple traumatic rib fractures had intensive pain regardless of intravenous analgesia, and underwent unilateral serratus anterior plane block. Under ultrasound guidance, a dose of $0,4 \mathrm{mg} / \mathrm{kg}$ $0.25 \%$ levobupivacaine was given between the serratus anterior and latissimus dorsi muscles.

- Pain scores were recorded with numerical rating scale (NRS) before and one hour after the block. Thoracic trauma severity score ( TTSS ) and injury severity score ( ISS ) were also recorded.

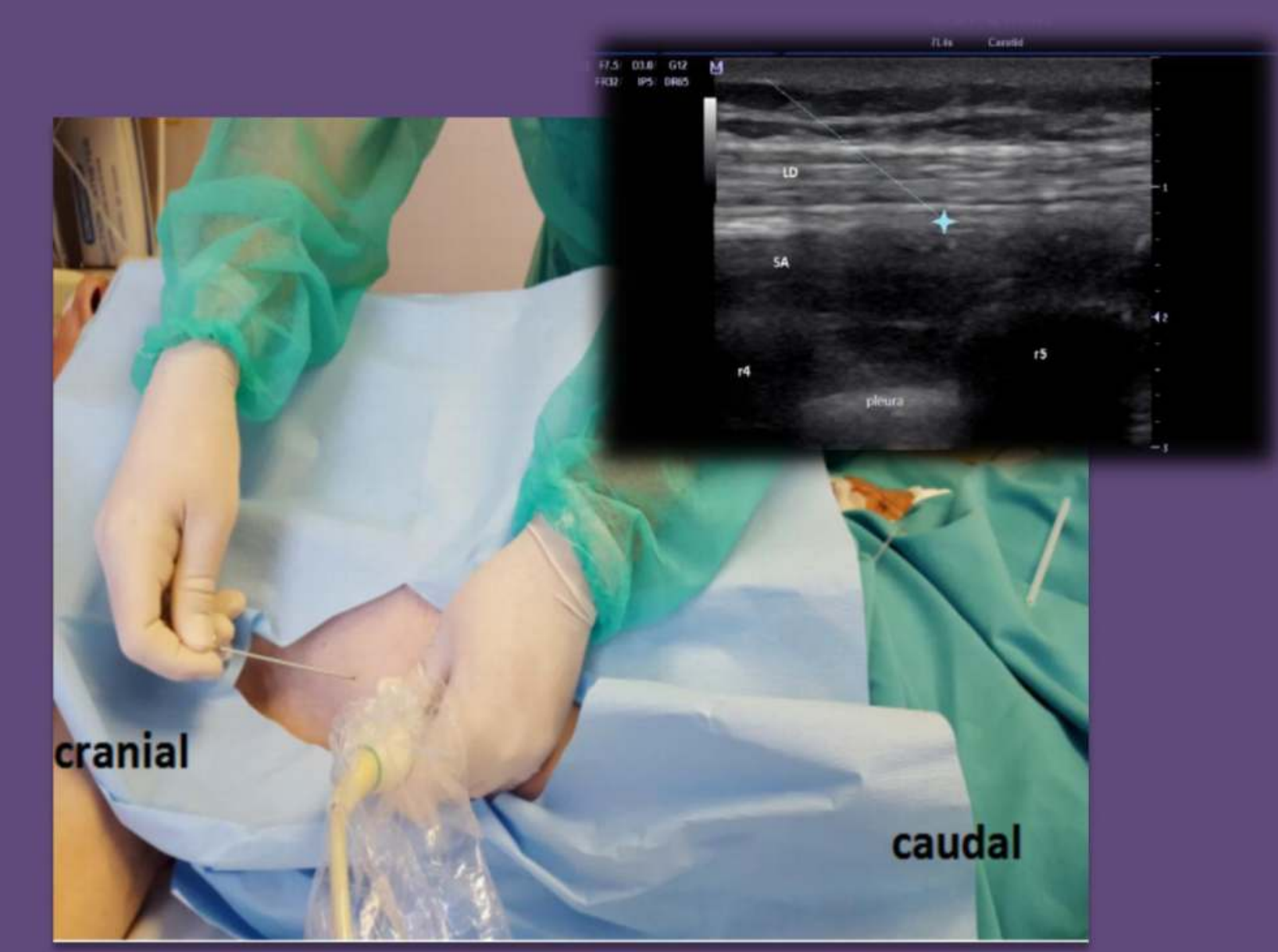

Figure 1. Serratus anteror plane block sonoanatomy (top), with block approach.

\section{Results}

- Patients average age was 53 years. Fracture of $1-3$ ribs was found in 2 patients and fracture of 3-6 ribs in 10 patients, with mean TTSS of 8,67 and mean ISS of 29,17 . Every patient reported reduction in their pain scores following the block within an hour. Mean NRS pain score before block was 8,41 and 3,58 after block. Wilcoxon signed rank test showed statistically significant differences between pain score before and after block $(p=0,002)$.

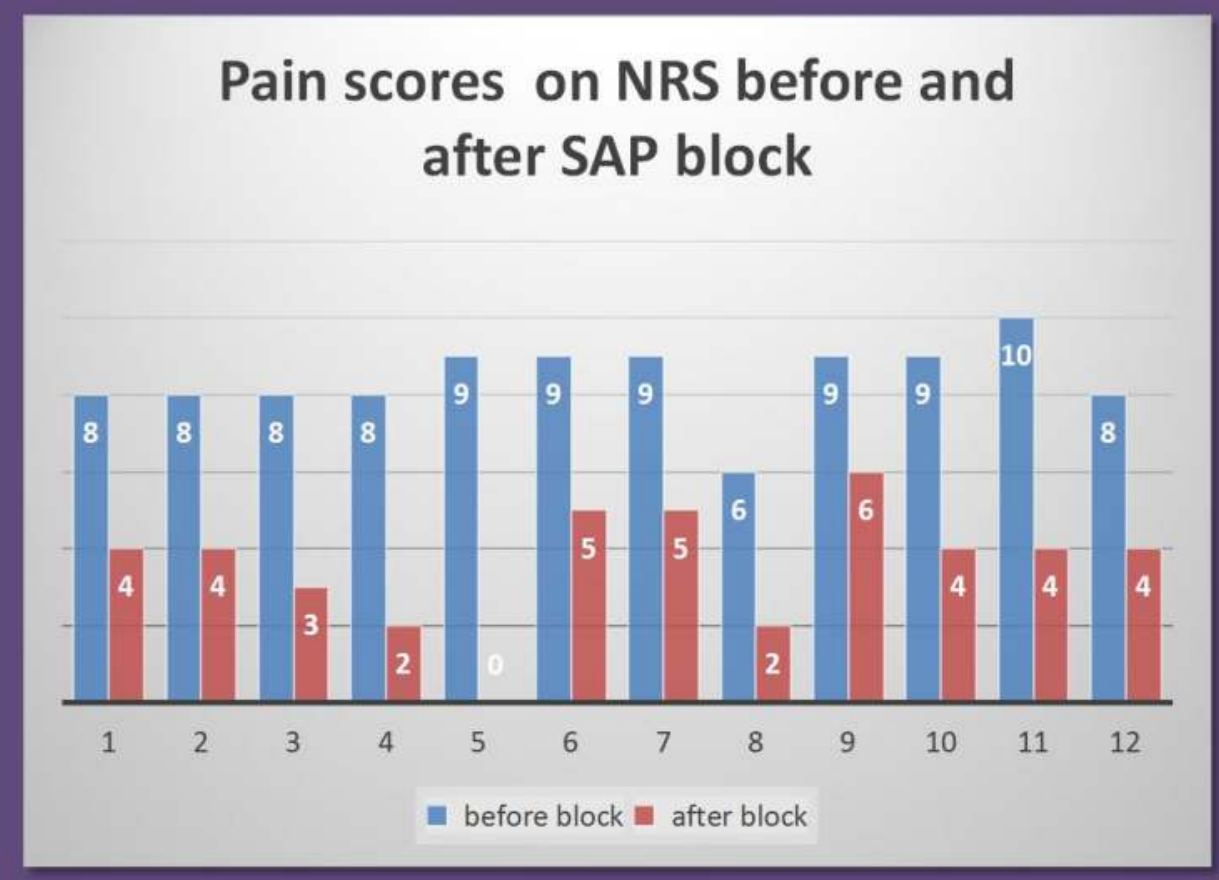

Chart 1. NRS pain scores before and after serratus anterior plane block

\section{Conclusion}

- Sertatus anterjor plane block can provjde effective analgesia in thoradic trauna patjents with nultiple rjb fractures, and can be alternative to thoracic epjdural and paravertebral blocks. 